\title{
Age, lighting treatment, feed allocation and feed form influence broiler breeder feeding time
}

\author{
R.M. Gous ${ }^{\#}$ \& R. Danisman \\ School of Agricultural, Earth and Environmental Sciences, University of KwaZulu-Natal, \\ Private Bag X01, Scottsville 3209, South Africa
}

(Received 20 January 2015; Accepted 9 December 2015; First published online 9 February 2016)

\begin{abstract}
Copyright resides with the authors in terms of the Creative Commons Attribution 2.5 South African Licence.
See: http://creativecommons.org/licenses/by/2.5/za

Condition of use: The user may copy, distribute, transmit and adapt the work, but must recognise the authors and the South African Journal of Animal Science.
\end{abstract}

\begin{abstract}
During a broiler breeder trial with 3200 Cobb 500 hens, the effects of lighting treatment after 20 weeks' feed allocation and of feed form on the length of time taken to consume the daily allocation of feed were measured. Pullets were reared on 8-hour photoperiods to 20 weeks, then transferred to one of four lighting treatments: permanently to $11 \mathrm{~h}$ or 16 hours, transferred temporarily to 11 hours, then given 2-hours increments at 40,44 and 48 weeks to reach 17 hours or a commercially recommended step-up lighting programme ( 11 hours at 20 weeks, incrementing by 30 min per week to reach $16 \mathrm{~h}$ by 30 weeks). Feed was made available in mash or pelleted form, and hens received $160 \mathrm{~g}$ or $180 \mathrm{~g}$ by 30 weeks. This allocation was increased linearly from $100 \mathrm{~g}$ at 20 weeks. After 40 weeks, the daily feed allocation was reduced by $5 \mathrm{~g} / \mathrm{bird}$ for each $5 \%$ reduction in rate of lay to a minimum of 150 or $160 \mathrm{~g} / \mathrm{bird}$. On five occasions, when the hens were $39,40,41,45$ and 54 weeks old, the time taken by the hens to consume all their feed was measured and scaled to $\mathrm{min} / 100 \mathrm{~g}$ consumed. Hens learned to consume the feed more rapidly as the laying period progressed. The mean clean-up time over all treatments was 67.7, 62.1, 63.4, 47.1 and $40.2 \mathrm{~min} / 100 \mathrm{~g}$ at the five ages. Over all treatments and ages, the time taken to consume all their feed was $40.0 \mathrm{~min} / 100 \mathrm{~g}$ for birds fed $160 \mathrm{~g}$, versus $72.2 \mathrm{~min}$ for those given $180 \mathrm{~g}$ of food daily, but this difference was greater at 39 weeks (43.5 versus 91.8) than at 54 weeks (34.0 versus $46.4 \mathrm{~min} / 100 \mathrm{~g}$, respectively). This effect was also evident with feed form, the difference in time taken to consume mash and pellets being greater at 39 weeks (69.2 versus 66.1) than at 54 weeks ( 54.7 versus $25.7 \mathrm{~min} / 100 \mathrm{~g}$, respectively). The lighting programmes also had an effect on the feed clean-up time. The main effects were 53.5, 56.3, 52.1 and $62.5 \mathrm{~min} / 100 \mathrm{~g}$ for the 11-hour constant, 11 to 16 hours, 16-hour constant and step-up programmes, respectively. Significant interactions occurred between treatments. The main reason was the much longer time taken initially by birds receiving the step-up lighting programme and $180 \mathrm{~g}$ of pelleted feed to consume all their feed. The effects of these treatments on bird welfare are discussed.
\end{abstract}

Keywords: Breeders, laying period, lipid reserves, welfare

\#Corresponding author: gous@ukzn.ac.za

\section{Introduction}

Broiler breeders are fed controlled amounts of feed daily to prevent them from becoming obese and to improve their egg output, compared with breeders given ad libitum access to food (Whitehead et al., 1987). Such a practice creates a welfare dilemma. The chronic feed restriction to which they are subjected results in stereotypical behaviours (Hocking et al., 2004; De Jong \& Jones, 2006; Sandilands et al., 2006; De Jong \& Guémené, 2009) that are positively correlated to the degree of restriction (Savory \& Maros, 1993) and are characteristic of frustration of feeding motivation (Duncan \& Wood-Gush, 1972). However, they lead to decreases in lipid deposition, heart disease, skeletal lameness, mortality, multiple ovulations and feed costs. Also, male and female fertility are improved by feed restriction (Duncan \& Hawkins, 1988). Aggressive pecking associated with hunger is increasing in prevalence in commercial flocks of broiler breeders, which is also detrimental to bird welfare (Jones et al., 2004). Methods by which breeder hens could be encouraged to spend more time at the feeder would reduce the negative effects of feed restriction. These have been explored with qualitative restriction through adding inert fillers to the feed such as oat hulls, sugar-beet pulp and sawdust (Mench, 1993; Savory et al., 1993; 1996; De Jong et al., 2005a; Nielsen et al., 2011). In researching an alternative method to improve welfare, De Jong et al. (2005b) and De Jong \& Van Krimpen 
(2011) reported that scattering feed on the floor once or twice daily did not improve the physiological indicators of stress and hunger. More recently, Van Emous et al. (2013) found no improvement in bird welfare by rearing breeders to a 20 -week bodyweight that was higher than that recommended by breeding companies. On the other hand, a low dietary protein level prolonged feeding time and reduced stereotypical behaviour during rearing, but not in the laying period.

Generally, research on feed restriction and bird welfare in broiler breeders has been conducted during the growing period rather than when the birds are in lay and consensus is that qualitative feed restriction does not improve bird welfare (Savory et al., 1996).

In a commercial breeder operation, it is unlikely that each hen in the flock would receive the average amount of feed allocated, as competition at the feed trough is considerable because of the limited amount of food made available to the flock. An important management objective, apart from welfare aspects, is to try to ensure that all birds have equal access to feed. This can be achieved in various ways, such as providing more feeding space, moving food around the house more rapidly, scattering feed on the floor with spinners, and diluting the feed so that the volume is increased, thus increasing feeding time (Sandilands et al., 2006).

In the many broiler breeder trials conducted in the facility over the past 10 years the authors noted that the 'clean-up' time, that is, the time that it takes for the feed trough to be emptied, varies from pen to pen and between treatments and ages, and depends on the prevailing environmental temperature. During one of these trials (Lewis et al., 2007) the researchers monitored the effects of feed allocation and feed form on the time taken to consume the daily feed. This paper reports these effects on feed clean-up time.

\section{Materials and Methods}

A total of 3200 Ross broiler breeder females were reared in seven lightproof litter-floor rooms on 8-hour photoperiods, after two days of continuous illumination. They achieved a mean bodyweight of $2.1 \mathrm{~kg}$ at 20 weeks. At this age they were randomly allocated to eight adult litter-floor rooms, each room being divided into four pens of 100 females and, subsequently, 10 males (reared separately from the females). Two rooms (800 birds) were transferred permanently to 11-hour photoperiods; two rooms to 16 hour photoperiods; two rooms were transferred temporarily to 11 hours, then given 2-hour increments at 40, 44 and 48 weeks to reach 17 hours; and two rooms were given a commercially recommended step-up lighting programme (11 hours at 20 weeks, incrementing by 30 min per week to 16 hours by 30 weeks). At day-old, all birds were fed a $210 \mathrm{~g} \mathrm{CP} / \mathrm{kg}, 12.4 \mathrm{MJ}$ AME/kg crumbled diet ad libitum in feeders until controlled feeding was introduced at three weeks, and then a $175 \mathrm{~g} \mathrm{CP} / \mathrm{kg}, 11.9 \mathrm{MJ}$ AME/kg pelleted diet (scattered on the litter floor) for three weeks. The diet specifications were changed to $140 \mathrm{~g} \mathrm{CP} / \mathrm{kg}, 11.5 \mathrm{MJ}$ AME/kg at 6 weeks, and to a $145 \mathrm{~g} \mathrm{CP} / \mathrm{kg}, 11.5 \mathrm{MJ}$ AME/kg layer diet from 5\% egg production onwards. This was delivered in two feed troughs per pen, which allowed $125 \mathrm{~mm}$ linear trough space per hen (and was fitted with a male excluder grid). Within each pen, the daily feed allocation was increased progressively to a peak of 160 $\mathrm{g} / \mathrm{bird} / \mathrm{d}$ at 26 weeks $(160 \mathrm{~g}$ ) or $180 \mathrm{~g} / \mathrm{bird} / \mathrm{d}$ at 30 weeks (180 g) (Figure 1). Within each allocation treatment, feed was provided as mash or 4-mm pellets. All four feed allocations $x$ form combinations were represented in each room. After 40 weeks, the daily feed allocation was reduced by $5 \mathrm{~g} /$ bird for each $5 \%$ reduction in rate of lay to a minimum of 150 or $160 \mathrm{~g} /$ bird (Figure 1).

On five occasions, when the hens were $39,40,41,45$ and 54 weeks old, the time taken by the hens to consume all the feed in the two troughs in each pen was measured by recording the time that feed was allocated and again when no feed remained.

As the amount of feed was reduced during the laying period, data were adjusted by determining the clean-up time in minutes per $100 \mathrm{~g}$ of feed. This unit was used in the statistical analyses. Data were subjected to a general linear model ANOVA from Genstat ninth edition (Lawes Agricultural Trust, 2006) using age, lighting, feed form and feed allocation as variables, and four-way interactions for all parameters. Linear regression with groups was used to determine the effects of lighting, feed form and feed allocation over the laying period on the time taken to consume the daily feed allocation.

\section{Results}

Considerable differences were evident in the length of time taken to empty the feed troughs with each of the treatments (Table 1). The extent of these differences diminished over the laying period, with the mean clean-up time over all treatments being $67.7,62.1,63.4,47.1$ and $40.2 \mathrm{~min} / 100 \mathrm{~g}$ at $39,40,41,45$ and 54 weeks old, respectively. Over all treatments and ages, the time taken to consume all feed allocated was 40.0 $\mathrm{min} / 100 \mathrm{~g}$ for birds fed $160 \mathrm{~g}$ versus $72.2 \mathrm{~min}$ for those given $180 \mathrm{~g}$ of food daily. This difference was greater at 39 weeks ( 43.5 versus 91.8) than at 54 weeks (34.0 versus $46.4 \mathrm{~min} / 100 \mathrm{~g}$, respectively). This effect was also evident with feed form. The difference in time taken to consume mash and pellets was greater at 39 weeks (69.2 versus 66.1) than at 54 weeks (54.7 versus $25.7 \mathrm{~min} / 100 \mathrm{~g}$, respectively). The lighting programmes also had an effect on the feed clean-up time. The main effects were 53.5, 56.3, 52.1 and 62.5 
min/100 $\mathrm{g}$ for the 11-h constant, 11 to $16 \mathrm{~h}, 16$-h constant and step-up programmes, respectively. Interactions occurred between the treatments, some of which, such as between feed form and allocation, disappeared towards the end of the laying period (Table 1 ).

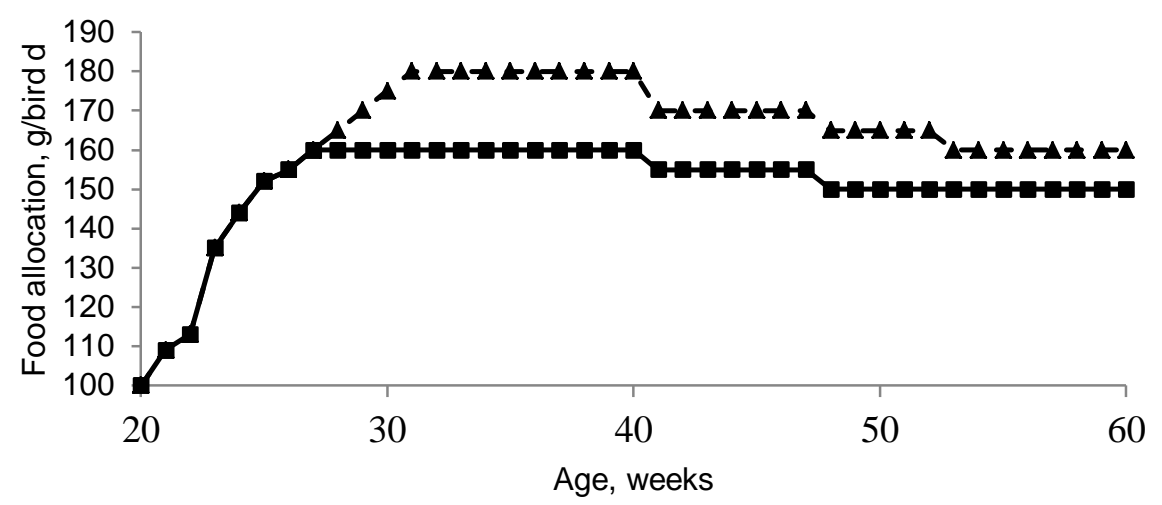

Figure 1 Mean daily feed intake for Cobb broiler breeder females restricted to a peak daily allocation of 160 or $180 \mathrm{~g} / \mathrm{bird}$ and with the reduction in intake after 40 weeks being related to the rate of lay on each treatment.

Table 1 Mean feed clean-up times (min per $100 \mathrm{~g}$ feed) at five ages when broiler breeders were fed mash or pellets and one of two feed allocations per day

\begin{tabular}{|c|c|c|c|c|c|c|c|c|c|c|}
\hline \multirow{3}{*}{$\begin{array}{l}\text { Age } \\
\text { (weeks) }\end{array}$} & \multirow{3}{*}{ Feed form } & \multicolumn{8}{|c|}{ Lighting programme after 20 weeks old } & \multirow{3}{*}{ Mean } \\
\hline & & \multicolumn{2}{|c|}{$11 \mathrm{~h}$ constant } & \multicolumn{2}{|c|}{11 to $17 \mathrm{~h}$} & \multicolumn{2}{|c|}{$16 \mathrm{~h}$ constant } & \multicolumn{2}{|c|}{ Step-up } & \\
\hline & & $160 \mathrm{~g}$ & $180 \mathrm{~g}$ & $160 \mathrm{~g}$ & $180 \mathrm{~g}$ & $160 \mathrm{~g}$ & $180 \mathrm{~g}$ & $160 \mathrm{~g}$ & $180 \mathrm{~g}$ & \\
\hline \multirow{2}{*}{39} & Mash & 63.1 & 86.1 & 54.7 & 72.8 & 50.9 & 75.6 & 64.4 & 82.2 & 69.2 \\
\hline & Pellet & 25.0 & 88.3 & 27.8 & 105 & 29.7 & 96.9 & 28.4 & 128 & 66.2 \\
\hline \multirow{2}{*}{40} & Mash & 60.9 & 77.8 & 67.5 & 61.9 & 51.9 & 72.5 & 64.4 & 76.9 & 66.7 \\
\hline & Pellet & 26.9 & 74.2 & 24.7 & 91.1 & 23.1 & 75.8 & 27.5 & 117 & 57.5 \\
\hline \multirow{2}{*}{41} & Mash & 58.4 & 80.6 & 57.7 & 68.8 & 53.9 & 75.3 & 68.4 & 81.8 & 68.1 \\
\hline & Pellet & 25.5 & 70.9 & 26.1 & 88.2 & 27.7 & 81.2 & 29.0 & 122 & 58.8 \\
\hline \multirow{2}{*}{45} & Mash & 50.7 & 60.9 & 26.8 & 60.0 & 47.7 & 62.4 & 47.1 & 65.9 & 56.4 \\
\hline & Pellet & 21.9 & 39.1 & 27.4 & 71.8 & 19.0 & 48.8 & 15.5 & 59.4 & 37.8 \\
\hline \multirow{2}{*}{54} & Mash & 51.0 & 66.6 & 47.3 & 55.0 & 44.7 & 56.9 & 55.7 & 60.3 & 54.7 \\
\hline & Pellet & 19.3 & 22.2 & 20.0 & 41.9 & 17.0 & 32.5 & 17.3 & 35.9 & 25.7 \\
\hline Mean & & 40.3 & 66.7 & 41.0 & 71.6 & 36.6 & 67.7 & 42.1 & 82.9 & \\
\hline
\end{tabular}

Standard error of the mean (SEM) for main effect of lighting programme: 1.358 (80 d.f.).

SEM for main effects of feed allocation and form: 0.96 (80 d.f.).

SEM for main effect of age: 1.518 (80 d.f.).

SEM for 4-way interaction: 6.071 (40 d.f.).

The interaction between feed form and allocation $(P<0.01)$ was the result of birds on $180 \mathrm{~g}$ and pelleted feed gradually learning to consume faster, resulting in interactions between feed form and time $(P$ $<0.01)$ and feed allocation and time $(P<0.01)$. For the first four measuring ages, the birds given $160 \mathrm{~g}$ and mash took more than twice as long to finish the feed as those fed $160 \mathrm{~g}$ and pellets. However, those hens fed $180 \mathrm{~g}$ and mash took less time to consume all the feed than hens fed $180 \mathrm{~g}$ and pellets. There was no longer an interaction by 54 weeks' old, when hens fed mash, over both feed allocations, took 55 min to consume 100 versus $26 \mathrm{~min} / 100 \mathrm{~g}$ for those fed pelleted feed. 
Using simple linear regression with groups, it could be demonstrated that the time required to deplete the feed in the trough for both feed forms when $160 \mathrm{~g}$ was fed declined at a rate of $(-) 0.774( \pm 0.332)$ $\mathrm{min} / 100 \mathrm{~g}$ per week, the constant term being $89.9 \pm 14.6$. Where $180 \mathrm{~g}$ and mash were fed, the slope and constant term were the same as for both $160 \mathrm{~g}$ treatments. Where $180 \mathrm{~g}$ and pellets were fed, the constant term was increased by $186( \pm 20.7) \mathrm{min} / 100 \mathrm{~g}$ and the regression coefficient reduced by a further $3.818( \pm$ 0.469 ) to $-4.59 \mathrm{~min} / 100 \mathrm{~g}$ per week. These linear relationships are illustrated in Figure 2.

\section{Discussion}

Although this trial was not designed to measure the effect on performance of quantitatively restricting breeder hens, the treatments enabled the researchers to quantify the effects of feed form and feed allocation on the amount of time spent by broiler breeder females in consuming their daily allowance. Therefore, contrary to research conducted previously, feed quality in this trial was the same in all treatments. Thus basal feed was not diluted. Feeding greater quantities of the same feed may have consequences on reproductive performance, but comparing rates of lay and egg weight between treatments was not the objective in this paper. Such comparisons have been published in the past (Lewis et al., 2007).

The most interesting results were that the rate at which food was consumed increased as the laying period progressed. Pelleted feed, not surprisingly, was consumed more rapidly than mash. Hens that were subjected to an increase in photoperiod from 11 to 16 hours over 10 weeks and fed $180 \mathrm{~g}$ pellets took considerably longer to consume the daily allocation at 39, 40 and 41 weeks old than hens on any of the other treatment combinations. These observations are discussed below.

The amount of feed allocated to the hens was reduced from 40 weeks old, based on decreases in the rate of laying. Thus the amount of time taken to consume $100 \mathrm{~g}$ feed was used as the criterion for comparison rather than the time taken to clean up all the feed. In spite of using this criterion, the length of time taken to consume $100 \mathrm{~g}$ of feed decreased as the hens aged. This would not be the result of a greater need for feed, as the rate of lay declined steadily throughout the trial, but probably reflects the ability of a broiler breeder to gradually adopt a faster rate of consumption. It is possible that initially, when faced with $180 \mathrm{~g}$ of feed, the birds had difficulty in consuming all the feed in one bout, preferring to return later to feed again. Certainly, it appeared that the birds fed $180 \mathrm{~g}$ in pelleted form would not consume the daily allocation at once, but returned later, taking longer to consume all the feed, even than those fed the same amount in mash. However, in all other combinations of feed allocation and form, the time taken to consume all the feed declined by $0.774 \mathrm{~min} / 100 \mathrm{~g}$ per week, resulting in a mean decrease of $11.6 \mathrm{~min}$ over the 16 weeks.

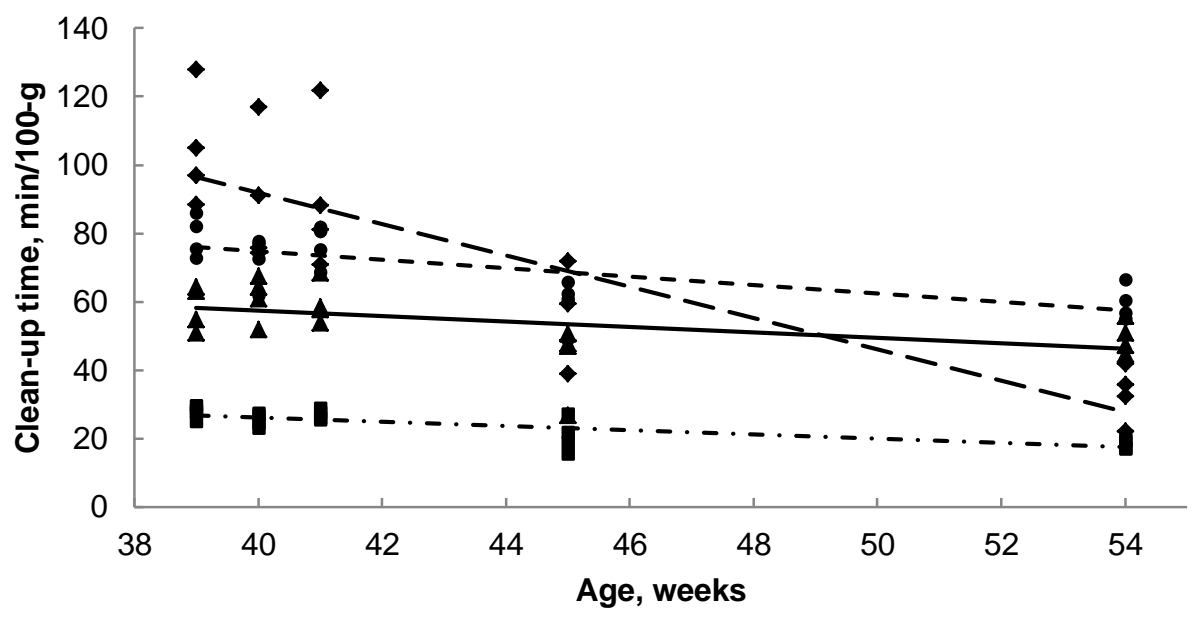

Figure 2 Feed clean-up time related to the amount of feed allocated to each hen daily $(160 \mathrm{~g}$ mash, $\boldsymbol{\Lambda}$ and solid line; $160 \mathrm{~g}$ pellets, $\mathbf{n}$ and dot-dash line; $180 \mathrm{~g}$ mash, •and dashed line; $180 \mathrm{~g}$ pellets, $\bullet$ and long dashes) over five sampling periods (39, 40, 41, 45 and 54 weeks old).

The significant interactions between lighting programme and feed form $(P<0.01)$, lighting programme and feed allocation $(P<0.01)$ and three-way interactions among light, feed allocation and feed form $(P<0.01)$ and among feed allocation, feed form and age $(P<0.01)$ were mainly the result of the long period initially taken by birds on the step-up lighting programme fed $180 \mathrm{~g}$ in the pelleted form to consume all their feed. The mean clean-up times for this treatment over the five ages were 128, 117, 121, 59 and $36 \mathrm{~min} / 100 \mathrm{~g}$, as 
opposed to those by hens from the same lighting treatment and receiving $160 \mathrm{~g}$ of pellets, whose clean-up times were $28,28,29,16$ and $17 \mathrm{~min} / 100 \mathrm{~g}$, respectively. It is not known why the step-up lighting treatment should have had such an effect on the time required to consume the food. The amount of light and feed that hens on this treatment had been receiving for nine weeks before the first measurement was made was the same as that imposed on birds on the constant 16-hour treatment. Egg production on this treatment was similar to that on the other lighting treatments, so the nutrient requirements per day were no less than on other treatments. The clean-up times for the birds receiving $180 \mathrm{~g}$ and pellets on the step-up treatment were consistent in both replicate pens. These were, 128 and 129 min at 39 weeks 111 and 122 at 40 weeks, 116 and 127 at 41 weeks, dropping to 52 and 66 min at 45 weeks, then to 37 and $35 \mathrm{~min} / 100 \mathrm{~g}$ at 54 weeks. Thus the delay was not the result of one of the replicate pens on this treatment receiving adverse conditions.

It was not surprising that in the three other combinations of feed form and feed allocation hens fed pellets consumed their daily allocation in less time than those fed mash. This phenomenon has been reported many times in the past (Jensen et al., 1962; Savory 1988). It is the reason that is given for the improved feed conversion efficiency seen in broilers receiving pellets, as opposed to mash, resulting from the extra time spent by birds eating mash. Feeding pellets to broiler breeders would tend to increase the time spent on stereotypical behaviour and would not improve bird welfare. The extra time taken to consume the $180 \mathrm{~g}$ of pelleted feed by hens on the step-up programme was contrary to the results of the other lighting treatments. This effect may be worth exploring as a means of slowing down the rate of food consumption in broiler breeders.

\section{Conclusions}

To reduce behaviours indicative of frustration, boredom and hunger, such as stereotypical object pecking, mash feed would be preferred over pelleted, and a greater feed allowance would lengthen the time spent by broiler breeders at the feed trough. The effect of a step-up pattern of lighting on the time taken to consume $180 \mathrm{~g}$ of pelleted feed might be worth investigating, given that this treatment caused the hens to reduce the rate of feed consumption.

\section{Acknowledgements}

The authors acknowledge the financial contribution for this and the related project from the National Research Foundation, Protein Research Foundation and Cobb Vantress, Siloam Springs, USA.

\section{Authors' contributions} the paper.

$\mathrm{RD}$ conducted the research as part of her MSc Agric programme. RMG designed and analysed the trial and wrote

\section{References}

De Jong, I.C. \& Jones, B., 2006. Feed restriction and welfare in domestic birds. In: Feeding in Domestic Vertebrates. Ed: Bels, V., Wallingford, UK, CABI. pp. 120-135.

De Jong, I.C. \& Guémené, D., 2009. Welfare issues in broiler breeders. Poultry Welfare Symposium Cervia, Italy. pp. 120-127.

De Jong, I.C. \& Van Krimpen, M.M., 2011. Feeding broiler breeders in relation to welfare aspects. Proc. 18th Eur. Symp. Poult. Nutr., Cesme, Turkey. pp. 230-241.

De Jong, I.C., Enting, HOUR., Van Voorst, S. \& Blokhuis, H.J., 2005a. Do low-density diets improve broiler breeder welfare during rearing and laying? Poult. Sci. 84, 194-203.

De Jong, I.C., Fillerup, M. \& Blokhuis, H.J., 2005b. Effect of scattered feeding and feeding twice a day during rearing on parameters of hunger and frustration in broiler breeders. Appl. Anim. Behav. Sci. 92, 61-76.

Duncan, I.J.H. \& Wood-Gush, D.G.M., 1972. Thwarting of feeding behaviour in the domestic fowl. Anim. Behav. 20, 444-451.

Duncan, I.J.H. \& Hawkins, P., 1988. The welfare of domestic fowl and other captive birds. In: Report on the Welfare of Broiler Breeders. Farm Animal Welfare Council, Surbiton, UK.

Hocking, P.M., Maxwell, M.H., Robertson, G.W. \& Mitchell, M.A., 2004. Welfare assessment of broiler breeders that are food restricted after peak rate of lay. Br. Poult. Sci.43, 5-15.

Jensen, L.S., Merrill, L.H., Reddy, C.V. \& McGinnis, J., 1962. Observations on eating patterns and rate of passage of birds fed pelleted and unpelleted diets. Poult. Sci. 41, 1414-1419.

Jones, E.K.M., Zaczek, V., McLeod, M. \& Hocking, P.M., 2004. Genotype, dietary manipulation and food allocation affect indices of welfare in broiler breeders. Br. Poult. Sci. 45, 725-737.

Lawes Agricultural Trust, 2006. Genstat 9th ed., Version 6.1.0.205. VSN International, Oxford, UK.

Lewis, P.D., Gous, R.M., Ghebremariam, W.K. \& Sharp, P.J., 2007. Broiler breeders do not respond positively to photoperiodic increments given during the laying period. Br. Poult. Sci. 48, 245-252.

Mench, J.A., 1993. Assessing welfare: An overview. J. Agric. Env. Ethics 6 (Special ed., Vol. 2), 68-75. 
Sandilands, V., Tolkamp, B.J., Savory, C.J. \& Kyriazakis, I., 2006. Behaviour and welfare of broiler breeders fed qualitatively restrictive diets during rearing: Are there alternatives to quantitative restriction? Appl. Anim. Behav. Sci. 96, 53-67.

Savory, C.J., 1988. Rates of eating by domestic fowls in relation to changing food deficits. Appetite 10, 57-65.

Savory, C.J. \& Maros, K., 1993. Influence of degree of food restriction, age and time of day on behaviour of broiler breeder chickens. Behav. Proc. 29, 179-190.

Savory, C.J., Hocking, P.M., Mann, J.S. \& Maxwell, M.H., 1996. Is broiler breeder welfare improved by using qualitative rather than quantitative food restriction to limit growth rate? Anim. Welf. 5, 105-127.

Van Emous, R.A., Kwakkel, R.P., Van Krimpen, M.M. \& Hendriks, W.H., 2013. Effects of growth patterns and dietary crude protein levels during rearing on body composition and performance in broiler breeder females during the rearing and laying period. Poult. Sci. 92, 2091-2100.

Whitehead, C.C., Herron, K.M. \& Waddington, D., 1987. Reproductive performance of dwarf broiler breeders given different food allowances during the rearing and breeding periods on two lighting patterns. Br. Poult. Sci. 28, 415-427. 